\title{
The AgNORs count in predicting long-term survival in serous ovarian cancer
}

\author{
Leszek Gottwald ${ }^{1}$, Marian Danilewicz ${ }^{2}$, Wojciech Fendler ${ }^{3}$, Jacek Suzin ${ }^{4}$, Michal Spych ${ }^{1}$, \\ Janusz Piekarski ${ }^{5}$, Wieslaw Tylinski ${ }^{4}$, Justyna Chalubinska ${ }^{1}$, Katarzyna Topczewska-Tylinska ${ }^{6}$, \\ Aleksandra Cialkowska-Rysz ${ }^{7}$
}

\author{
1Department of Radiotherapy, Chair of Oncology, Medical University of Lodz, Poland \\ 2Department of Nephropathology, Division of Morphometry, Medical University \\ of Lodz, Poland \\ ${ }^{3}$ Department of Pediatrics, Oncology, Hematology and Diabetology, Medical University \\ of Lodz, Poland \\ 4Department of Gynecology and Gynecologic Oncology, I Chair of Obstetrics \\ and Gynecology, Medical University of Lodz, Poland \\ ${ }^{5}$ Department of Surgical Oncology, Chair of Oncology, Medical University of Lodz, \\ Poland \\ 6Department of Health Care Policy, Medical University of Lodz, Poland \\ 7Palliative Care Unit, Chair of Oncology, Medical University of Lodz, Poland
}

Submitted: 22 January 2011

Accepted: 9 June 2011

Arch Med Sci 2014; 10, 1: 84-90

DOI: 10.5114 /aoms.2013.36753

Copyright (C 2014 Termedia \& Banach

\section{Abstract}

Introduction: The value of argyrophilic nucleolar organizer regions (AgNORs) to predict survival in patients with ovarian cancer has not been clearly explained yet. The aim of study was to assess the value of analysis of the mean number of AgNORs per nucleus (mAgNOR) and mean percentage of nuclei with five or more AgNORs per nucleus (pAgNOR) in the prediction of disease-free survival (DFS) and overall survival (OS) in patients with serous ovarian cancer.

Material and methods: The study examined 52 patients treated for serous ovarian cancer with a follow-up period of 2-143 months. After silver staining paraffin specimens from primary surgery, mAgNOR and pAgNOR in cancer cells were counted and analyzed. Age, grading, radicality of surgery and FIGO staging were analyzed as covariates.

Results: Mean mAgNOR equaled $4.4 \pm 0.9$ and pAgNOR equaled $42.2 \pm 20.8 \%$. Both $\mathrm{mAgNOR}$ and $\mathrm{pAgNOR}$ were the lowest in G1 tumors. The mAgNOR and pAgNOR were lower in stage I than stage IV cancers. The DFS and OS rates were respectively $15.4 \%$ and $21.2 \%$. In univariate analysis FIGO staging, grading, and pAgNOR were associated with worse prognosis, while radicality of surgery remained a significant protective factor in terms of DFS. Higher FIGO staging and older age worsened OS. In multivariate analysis FIGO staging remained significantly associated with both DFS (HR 1.98; 95\% CI 1.05-3.71) and OS (HR 1.76; 95\% Cl 1.00-3.10), while age affected OS rates (HR 1.78; 95\% Cl 1.04-2.95).

Conclusions: mAgNOR and pAgNOR are useful markers of cellular kinetics. Prospective studies in larger populations are needed to confirm these results in terms of AgNORs' effects on survival.

Key words: nucleolar organizer regions, argyrophilic, serous ovarian cancer, prognostic factors, survival.

\section{Introduction}

Ovarian cancer is the fourth leading cause of all deaths due to malignant neoplasms in women, after cancer of the breast, lung and bowel. Its

\author{
Corresponding author: \\ Leszek Gottwald MD, PhD \\ Department of Radiotherapy \\ Chair of Oncology \\ Medical University of Lodz \\ 4 Paderewskiego St \\ 93-509 Lodz, Poland \\ Phone: +48 426895551 \\ Fax: +48 426895552 \\ E-mail: lgottwald@wp.pl
}


common histological type is primary serous adenocarcinoma [1]. Many studies have been devoted to identifying prognostic factors, and numerous features with varying degrees of accuracy have been proposed for ovarian cancer patients [1-4]. Generally, post-operative residual tumors have been described as the leading prognostic factor, with the type of adjuvant chemotherapy and platinum sensitivity being other independent indicators of relapse and survival [1, 2, 5]. However, the prognostic significance of some of the readily available clinical, laboratory and pathological factors such as age, serum markers, histological type, grade, and proliferative activity of the tumor has been debated [1].

The proliferative activity of neoplasms can be estimated by many methods, and the analysis of argyrophilic nucleolar organizer regions (AgNORs) is one of them [6-9]. The value of AgNORs as proliferation markers has been confirmed in many cancers such as ovarian, endometrial, cervical, breast, gastric, colorectal, oral, bladder, prostate, hepatocellular, and salivary gland cancer [10-20]. The NORs are segments of DNA that transcribe to ribosomal RNA and are situated on short arms of the acrocentric chromosomes 13, 14, 15, 21 and 22. The number of NORs reflects the transcriptional activity of cells, and is related to cell cycle stage. The quantity of interphase NORs increases in cycling cells from the early G1 phase to the late S phase. In cancer tissues, the NOR value is closely related to both the percentage of cycling and S-phase cells [21, 22].

The first reports of usefulness of AgNOR analysis as a diagnostic tool in oncology were published 30 years ago [22]. Since then, several studies have shown that the AgNOR count differs between benign and malignant tumors of various origins and in cancers with different histological grades $[8,10,14,16$, $23,24]$. The relationship between AgNOR count in many cancers and some clinical parameters such as staging, tumor size and distant metastasis has also been widely described $[9,20]$. The relationship between AgNOR count, age and performance status of the patients was not however determined. It is postulated that in benign tumors, the mAgNOR value varies between one and two, and an increased mAgNOR value positively correlates with the number of acrocentric chromosomes, increased amount of DNA and aneuploidy [23]. An mAgNOR value larger than three is thought to be a characteristic marker of malignant tumors [16, 25].

After silver staining, NORs can be easily identified as black dots exclusively situated throughout the nucleolar area, and are called AgNORs. NOR argyrophilia is due to a group of nucleolar proteins with a high affinity to silver. AgNOR analysis can be performed in three ways: I - the mean number of AgNORs per nucleus (mAgNOR); II - the mean percentage of nuclei with five or more AgNORs per nucleus (pAgNOR); III - the AgNORs area/nucleus ratio (sAgNOR) $[22,25,26]$. In this paper we analyze the AgNOR count as a function of mAgNOR associated with tumor ploidy, and pAgNOR, which is thought to be a proliferative activity index $[21,27]$. The results of sAgNOR analysis were reported previously [28].

The aim of the study was to assess the value of $m A g N O R$ and pAgNOR analysis in the prediction of disease-free survival (DFS) and overall survival (OS) in serous ovarian cancer.

\section{Material and methods}

The study examined 52 consecutive patients aged 24-83 years (mean: $57.1 \pm 14.5$ ) diagnosed and treated operatively for serious ovarian cancer in the Madurowicz Memorial Hospital of Lodz during 19982002. Adjuvant chemotherapy was conducted in the Regional Cancer Center of Lodz and in the Madurowicz Memorial Hospital of Lodz. Patients with incomplete follow-ups in November 2009 were excluded. Detailed clinical and pathological characteristics of the study group are presented in Table I.

The tissues from initial surgery were analyzed. Sections $4 \mu \mathrm{m}$ thick were cut from tissue blocks, previously routinely fixed in $10 \%$ buffered formalin and embedded in paraffin. One section was stained with hematoxylin and eosin for histopathologic diagnosis. Another section was stained according to the one-step AgNOR method described by Howell and Black [22] and Ploton et al. [26]: specimens were incubated in a mixture of one volume of $2 \%$ gelatin in $1 \%$ formic acid to two volumes of $50 \%$ silver nitrate and then washed ten times with deionized distilled water. Histological morphometry was performed by means of an image analysis system consisting of a PC equipped with an optical mouse, a Ver 2000 card (frame grabber, true color, real time), produced by ADDA Technologies (Taiwan), and a Panasonic color TV camera (Japan), coupled to a Carl Zeiss Jenaval microscope (Germany). This system was programmed (MultiScan software produced by Computer Scanning Systems, Poland) to calculate the surface area of the structure whose perimeter was traced, and the total number of objects (semi-automatic function).

Both the counting of AgNORs and the morphometric assessment were performed at 400x magnification. The AgNORs were seen as black or dark brown dots within the nucleus. The following parameters were estimated in 100 randomly chosen nuclei: (1) nuclear area and nuclear outline (the outer limit of a nuclear membrane was traced using the cursor of an optical mouse), (2) the number of AgNORs per nuclear area (these objects were automatically counted and then followed with manual correction, as needed). From these data, the analysis of mAgNOR and pAgNOR counts was conduct- 
Table I. mAgNOR and pAgNOR and selected clinical and histological parameters in patients with serous ovarian cancer

\begin{tabular}{|c|c|c|c|c|c|c|c|c|}
\hline \multirow[t]{2}{*}{ Parameter } & \multirow[t]{2}{*}{ Number } & \multirow[t]{2}{*}{ Percent } & \multicolumn{3}{|c|}{ mAgNOR } & \multicolumn{3}{|c|}{ pAgNOR } \\
\hline & & & Mean \pm SD & K-W & Post-hoc & Mean \pm SD & $\mathrm{K}-\mathrm{W}$ & Post-hoc \\
\hline \multicolumn{9}{|l|}{ Age [years] } \\
\hline$\leq 50(\mathrm{~A})$ & 14 & 26.9 & $4.6 \pm 0.9$ & \multirow[t]{3}{*}{$p=0.1462$} & \multirow[t]{3}{*}{ N/A } & $47.2 \pm 21.7$ & \multirow[t]{3}{*}{$p=0.0655$} & \multirow[t]{3}{*}{ N/A } \\
\hline $51-70(B)$ & 21 & 40.4 & $4.6 \pm 1.0$ & & & $46.8 \pm 21.9$ & & \\
\hline$>70(\mathrm{C})$ & 17 & 32.7 & $4.1 \pm 0.5$ & & & $32.2 \pm 15.9$ & & \\
\hline \multicolumn{9}{|l|}{ Grading } \\
\hline G1 & 13 & 25.0 & $3.8 \pm 0.2$ & \multirow[t]{3}{*}{$p \leq 0.0001^{*}$} & G1-G2 $p=0.14$ & $24.6 \pm 9.1$ & \multirow[t]{3}{*}{$p<0.0001^{*}$} & $\mathrm{G} 1-\mathrm{G} 2 p=0.20$ \\
\hline G2 & 15 & 28.8 & $4.2 \pm 0.6$ & & G1-G3 $p<0.001$ & $37.4 \pm 14.3$ & & G1-G3 $p<0.001$ \\
\hline G3 & 24 & 46.2 & $4.9 \pm 1.0$ & & G2-G3 $p=0.07$ & $54.5 \pm 21.3$ & & G2-G3 $p=0.06$ \\
\hline \multicolumn{9}{|c|}{ FIGO staging } \\
\hline$I^{\star *}$ & 9 & 17.3 & $3.9 \pm 0.5$ & \multirow[t]{4}{*}{$p=0.07$} & \multirow[t]{4}{*}{ N/A } & $27.3 \pm 15.7$ & \multirow[t]{4}{*}{$p=0.08$} & \multirow[t]{4}{*}{ N/A } \\
\hline ॥ & 5 & 9.6 & $4.2 \pm 0.6$ & & & $40.2 \pm 21.1$ & & \\
\hline$\| I^{* \star}$ & 31 & 59.6 & $4.5 \pm 1.0$ & & & $44.4 \pm 20.9$ & & \\
\hline $\mathrm{IV} * *$ & 7 & 13.5 & $4.6 \pm 0.8$ & & & $49.8 \pm 20.5$ & & \\
\hline \multicolumn{9}{|c|}{ Radicality of surgery*** } \\
\hline $\mathrm{R}$ & 16 & 30.8 & $4.1 \pm 0.7$ & \multirow[t]{3}{*}{$p=0.21$} & \multirow[t]{3}{*}{$\mathrm{N} / \mathrm{A}$} & $35.8 \pm 22.6$ & \multirow[t]{3}{*}{$p=0.40$} & \multirow[t]{3}{*}{ N/A } \\
\hline$\overline{O C}$ & 30 & 57.7 & $4.6 \pm 1.0$ & & & $46.0 \pm 20.1$ & & \\
\hline SoC & 6 & 11.5 & $4.3 \pm 0.5$ & & & $39.7 \pm 18.9$ & & \\
\hline \multicolumn{9}{|c|}{ Adjuvant treatment } \\
\hline No & 3 & 5.8 & $4.3 \pm 0.5$ & \multirow[t]{2}{*}{-} & \multirow[t]{2}{*}{-} & $43.7 \pm 22.0$ & \multirow[t]{2}{*}{-} & \multirow[t]{2}{*}{-} \\
\hline $\mathrm{CT}^{\star *}$ & 49 & 94.2 & $4.4 \pm 0.9$ & & & $42.0 \pm 21.1$ & & \\
\hline
\end{tabular}

${ }^{*}$ Statistical significance, ${ }^{* *}$ lower mAgNOR and pAgNOR values in FIGO stage I when compared to stage IV $(p=0.030 ; p=0.026)$ and lower pAgNOR value in FIGO stage I when compared to stage III $(p=0.029)$, ${ }^{* * *}$ paclitaxel + cisplatin, $R$ - radical, OC - optimal cytoreduction, SoC suboptimal cytoreduction

ed. Additional factors included in the analysis were age at diagnosis (categorized as $\leq 50 ; 51-70$ and $\geq 71$ years), clinical FIGO staging, radicality of surgery (1. radical: lack of residual tumor; 2 . optimal cytoreduction: $\leq 1.0 \mathrm{~cm}$ diameter of residual tumor; 3. suboptimal cytoreduction: $>1.0 \mathrm{~cm}$ diameter of residual tumor) and histological grading. The DFS was defined as the period from primary surgery until relapse. The OS was defined as the period from primary surgery until death or until the closing date of the study.

\section{Statistical analysis}

All data were analyzed using Statistica 9.0 PL software (StatSoft Inc., Tulsa, OK., USA). Due to the small and unequal sample sizes, the nonparametric analysis of variance (the Kruskal-Wallis test) was used for mAgNOR and SAgNOR analysis in groups of different age, extent of surgery, grade and clinical stage according to FIGO. Post-hoc testing using Bonferroni-corrected Mann-Whitney $U$ test was performed if statistical significance was obtained in analysis of variance. Kaplan-Meier survival curves are presented for mAgNOR and pAgNOR. Univariate Cox regression models were constructed for the analyzed variables potentially affecting OS and DFS. Multivariate models of survival for mAgNOR and pAgNOR were also developed to evaluate the role of confounding variables such as FIGO stage, grade, age of the patient and radicality of surgery. The mAgNOR and pAgNOR were tested in separate models to avoid redundancy as both variables were expected to be intrinsically correlated. A multivariate proportional hazard model (Cox) was used to test the prognostic value of features. A value of $p$ less than 0.05 was considered as significant.

\section{Results}

Mean mAgNOR and pAgNOR equaled $4.4 \pm 0.9$ and $42.2 \pm 20.8 \%$ respectively. The statistical analysis of the mAgNOR and the pAgNOR as a function of age at diagnosis, histological grading, FIGO staging, radicality of surgery and adjuvant treatment is presented in Table I. Figure 1 demonstrates the AgNORs in $\mathrm{G} 2$ serous ovarian cancer.

Mean duration of the follow-up period was 44.6 \pm 43.4 months. The DFS rate was $15.4 \%$. In univariate 
analysis FIGO staging $(p=0.008)$, radicality of surgery $(p=0.032)$ and pAgNOR $(p=0.048$; Figure 2$)$ worsened DFS, grading showed borderline significance $(p=0.053)$, while mAgNOR $(p=0.404$; Figure 3$)$ and age category at diagnosis $(p=0.181)$ were not connected to DFS. The results of univariate analysis are presented in Table II. In multivariate analysis only FIGO staging remained significant.

During the follow-up 41 patients (78.8\%) died, and 11 patients $(21.2 \%)$ remain alive. The OS rate was $21.2 \%$. In univariate analysis FIGO staging $(p=0.010)$ and grading $(p=0.050)$ worsened OS, age category at diagnosis $(p=0.055)$ and radicality of surgery $(p=0.092)$ and pAgNOR $(p=0.082$; Figure 4) suggested a potential impact on OS, while mAgNOR ( $p=0.445$; Figure 5 ) was not shown to affect OS. The results of univariate analysis are presented in Table II. In multivariate analysis, OS was found to be significantly associated with FIGO staging and patient's age. The results of multivariate analysis are presented in Tables III and IV.

\section{Discussion}

Some reports describing the AgNORs in epithelial ovarian tumors exist in the literature [6, 9-11, 29, 30]. It has been confirmed that in epithelial ovarian tumors, mAgNOR and pAgNOR increase from benign to borderline and malignant neoplasms [9, 29, 30],

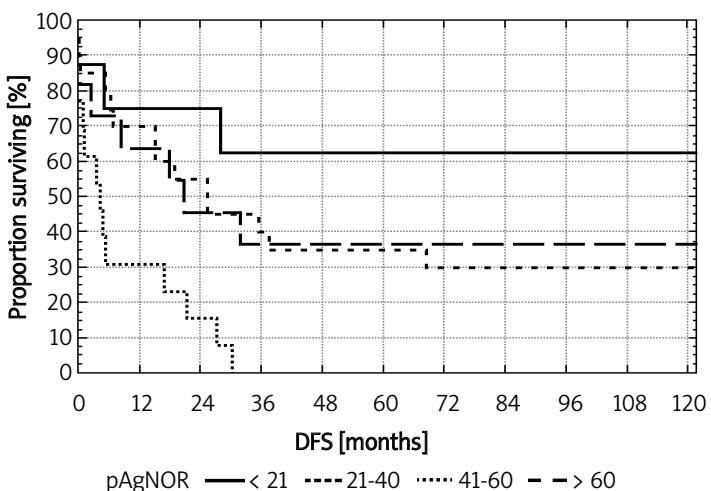

Figure 2. pAgNOR analysis and DFS

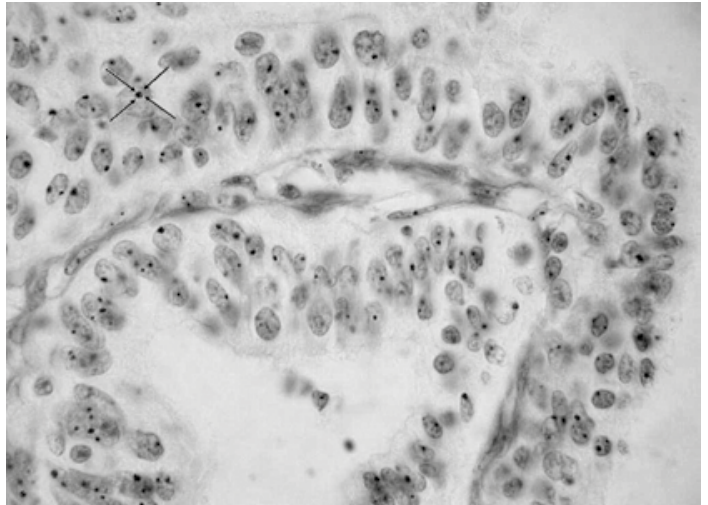

Figure 1. AgNORs in G2 serous ovarian cancer, 1000× magnification. After silver staining, NORs can be easily identified as black dots exclusively situated throughout the nucleolar area, and are called AgNORs (arrows)

while in cancers, the number also increases from $\mathrm{G} 1$ to $\mathrm{G} 3$ tumors [6, 9, 31]. This represents a close match with our findings that mAgNOR and pAgNOR were positively correlated with tumor grading. Opposite to $\mathrm{mAgNOR}$ and $\mathrm{pAgNOR}$, in our previous study we reported higher SAgNOR values in G1 cancers when compared to lower sAgNOR in G3 cancers [28]. It can be explained by the dynamic changes in the nuclear volume during the transformation from welldifferentiated to poorly differentiated carcinoma

Table II. DFS and OS in patients with serous ovarian cancer - univariate analysis

\begin{tabular}{|lcccccccc|}
\hline Parameter & \multicolumn{9}{c}{ DFS } & \multicolumn{5}{c}{ OS } \\
\cline { 2 - 9 } & $\begin{array}{c}\text { Hazard } \\
\text { ratio }\end{array}$ & \multicolumn{2}{c}{$\begin{array}{c}\text { 95\% Confidence } \\
\text { interval }\end{array}$} & Value of $p$ & $\begin{array}{c}\text { Hazard } \\
\text { ratio }\end{array}$ & $\begin{array}{c}95 \% \text { Confidence } \\
\text { interval }\end{array}$ & Value of $p$ \\
\hline $\begin{array}{l}\text { Age category } \\
\text { at diagnosis }\end{array}$ & 1.35 & 0.87 & 2.10 & 0.18 & 1.52 & 0.99 & 2.32 & 0.06 \\
\hline Radicality of surgery & 0.43 & 0.20 & 0.93 & $0.03^{*}$ & 0.51 & 0.23 & 1.12 & 0.09 \\
\hline Staging & 1.75 & 1.16 & 2.64 & $0.01^{*}$ & 1.78 & 1.15 & 2.76 & $0.01^{*}$ \\
\hline Grading & 1.47 & 0.99 & 2.17 & $0.05^{*}$ & 1.50 & 1.00 & 2.25 & $0.05^{*}$ \\
\hline mAgNOR & 1.14 & 0.84 & 1.54 & 0.41 & 1.13 & 0.83 & 1.54 & 0.45 \\
\hline pAgNOR & 1.03 & 1.01 & 1.06 & $0.05^{*}$ & 1.32 & 0.97 & 1.79 & 0.08 \\
\hline
\end{tabular}

*Statistical significance

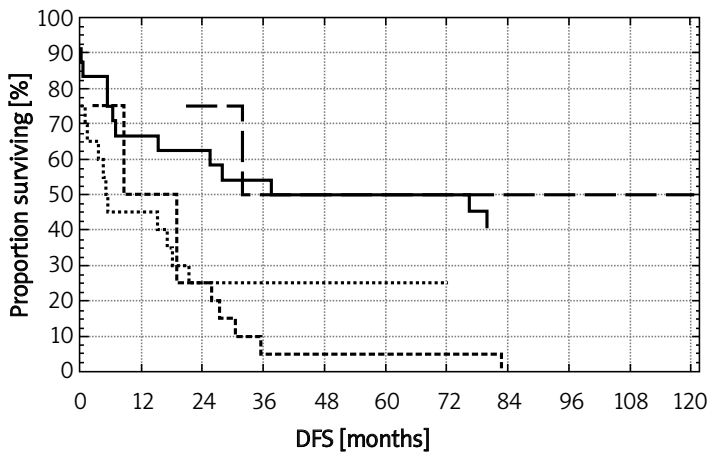

mAgNOR $-<4.01 \quad---4.01-5.00 \quad \cdots . . .5 .01-6.00 \quad->6.00$

Figure 3. mAgNOR analysis and DFS 


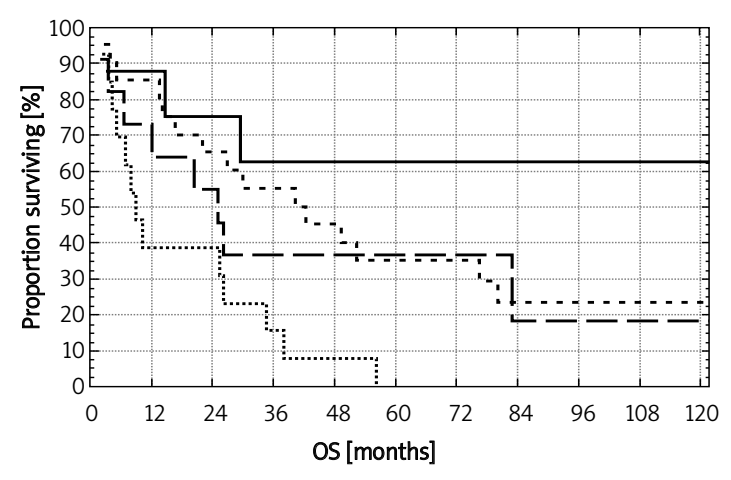

pAgNOR —<21 -.--21-40

Figure 4. pAgNOR analysis and OS

Table III. mAgNOR, DFS and OS - multivariate analysis

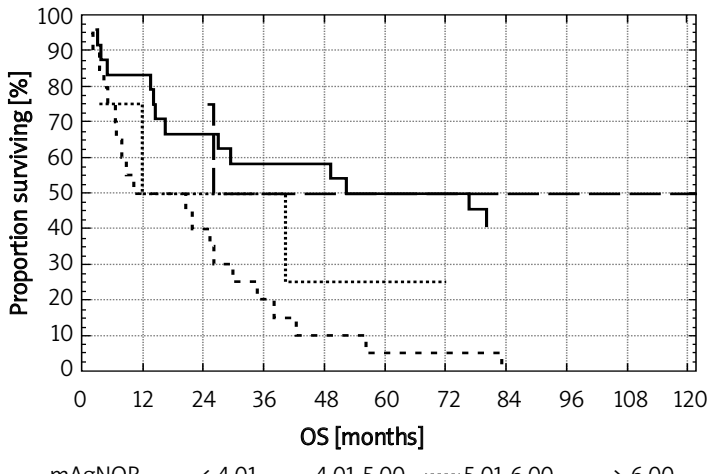

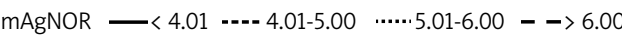

Figure 5. mAgNOR analysis and OS

Table IV. pAgNOR, DFS and OS - multivariate analysis

\begin{tabular}{|c|c|c|c|c|c|c|c|c|}
\hline \multirow{3}{*}{$\begin{array}{l}\text { Parameter } \\
\text { Age at diagnosis }\end{array}$} & \multicolumn{4}{|c|}{ DFS } & \multicolumn{4}{|c|}{ OS } \\
\hline & \multirow{2}{*}{$\begin{array}{c}\begin{array}{c}\text { Hazard } \\
\text { ratio }\end{array} \\
1.33\end{array}$} & \multicolumn{2}{|c|}{$\begin{array}{l}\text { 95\% Confidence } \\
\text { interval }\end{array}$} & \multirow{2}{*}{$\begin{array}{c}\text { Value of } p \\
0.33\end{array}$} & \multirow{2}{*}{$\begin{array}{c}\begin{array}{c}\text { Hazard } \\
\text { ratio }\end{array} \\
1.74\end{array}$} & \multicolumn{2}{|c|}{$\begin{array}{l}\text { 95\% Confidence } \\
\text { interval }\end{array}$} & \multirow{2}{*}{$\begin{array}{c}\text { Value of } p \\
0.06\end{array}$} \\
\hline & & 0.74 & 2.40 & & & 0.99 & 3.06 & \\
\hline Radicality of surgery & 1.05 & 0.69 & 1.59 & 0.84 & 0.95 & 0.62 & 1.46 & 0.82 \\
\hline Grading & 1.16 & 0.69 & 1.95 & 0.58 & 1.12 & 0.66 & 1.89 & 0.68 \\
\hline FIGO staging & 1.86 & 0.99 & 3.52 & 0.06 & 1.66 & 0.93 & 2.97 & 0.09 \\
\hline pAgNOR & 0.88 & 0.58 & 1.32 & 0.53 & 0.92 & 0.61 & 1.42 & 0.75 \\
\hline
\end{tabular}

cells. Despite the dynamic increase in the total number of AgNORs per tumor cell nuclei from G1 to G3 cancers [32], the rapid increase in cell volume may result in the decrease of SAgNOR from G1 to G3 cancers.

Previous data published by Ghazizadeh et al. [6] and Sah et al. [31] describe a positive correlation between AgNORs and clinical staging in patients with ovarian cancer. We found only lower mAgNOR and PAgNOR values in FIGO stage I when compared to stage IV and additionally pAgNOR when compared to stage III, but in our previous study of 69 primary serous ovarian cancers, we confirmed a significant association between mAgNOR, pAgNOR and staging [10]. The third parameter of the AgNORs analysis, sAgNOR, remains rather constant during the progression and dissemination of the neoplastic disease [28].
The significant value of AgNORs to predict longterm survival in patients with primary ovarian cancer has not been clearly explained yet. Our previous studies of mAgNOR and pAgNOR examined 39 patients with a short observation period from initial surgery to second-look laparotomy. Of these, 32 with completed long-term data were included in our present study. In these studies, a significant correlation between both the mAgNOR and the pAgNOR and the quantitative result of second-look laparotomy was postulated, and the higher number of AgNORs resulted in better response to adjuvant chemotherapy [33]. It is noteworthy that early relapses occur in tumors with high proliferative activity after remission, and generally the prognosis for these patients is worse compared to patients with lower proliferative activity [15, 17, 24, 34]. Analyzing long-term treatment results, Muso et al. 
found the mAgNORs to be significantly higher in 37 patients with progressive ovarian cancer of different histological types, despite postoperative chemotherapy, than in patients who underwent successful treatment [35]. Similarly, Sah et al. observed high AgNOR counts in a group of 84 patients with progressive disease, recurrence or death from tumor [31]. Our results confirm the possible significant value of pAgNOR, but not mAgNOR analysis in prediction of DFS, but not OS, in 52 ovarian cancer patients, all of the serous type. Our previous results of sAgNOR analysis on the same group of 52 patients did not confirm a significant association between SAgNOR and long-term survival [28].

There are some reports correlating AgNOR count and survival in patients suffering from cancers of non-ovarian origin [15, 17, 24, 34]. Chiusa et al., after analysis of 65 cases of prostate cancer in a 3-year follow-up, found patients with G2 prostate cancers and high AgNOR counts to have worse prognosis (similar to $\mathrm{G} 3$ cancers) when compared to $\mathrm{G} 2$ tumors with low AgNOR counts (similar to G1 cancers) [17]. Kumar et al. identified a significantly worse prognosis and need for more intensive treatment for patients with larger AgNOR counts when compared to patients with lower AgNOR counts [15]. Similar conclusions were postulated for colorectal and bladder cancers [24, 34].

Finally, the primary goal of a surveillance strategy in patients with serous ovarian cancer is to facilitate the early detection of the disease, but even in such cases the prognosis should be assessed very carefully. New technologies that have been developed over recent years, which enable more precise analysis of cellular proteins, e.g. MALDI mass spectrometry imaging, should be used to better characterize ovarian carcinogenesis and to recognize new prognostic factors in ovarian cancer [36].

Our findings show that the analysis of tumor markers such as AgNORs gives potentially significant information. The AgNOR count can be taken into consideration as a potential additional prognostic indicator in serous ovarian cancer. The low number of patients in our study should be taken into consideration, and the results interpreted with this in mind.

In conclusion, mAgNOR and PAgNOR are useful markers of cellular kinetics and good prognostic factors in serous ovarian cancer. The assessment of sAgNOR should be performed commonly with $m A g N O R$ and pAgNOR to better characterize the cancer. The small number of patients used for this study demands further prospective studies in larger populations to confirm these results.

\section{References}

1. Linasmita V, Pattaraarchachai J, Daengdeelert P. Prognostic factors for survival of epithelial ovarian cancer. Int J Gynaecol Obstet 2004; 85: 66-9.
2. Benedet JL, Bender H, Jones H 3rd, Ngan HY, Pecorelli S. FIGO staging classifications and clinical practice guidelines for gynaecological cancers. FIGO Committee on Gynecologic Oncology. Int J Gynaecol Obsetet 2000; 70: 209-62.

3. Ozgun MT, Turkyilmaz C. A giant ovarian mucinous cystadenoma in an adolescent: a case reprt. Arch Med Sci 2009; 5: 281-3.

4. Gora E, Zelazowski MJ, Gottwald L, Bienkiewicz A, Bednarek AK. Detection of circulating carcinoma in peripheral blood collected from patients with ovarian cancer by using different molecular markers - a preliminary report. Arch Med Sci 2006; 2: 101-7.

5. Milovic-Kovacevic M, Starnatovic L, Popov I, RadosevicJelic L, Kezic I. Platinum sensitive relapsed epithelial ovarian cancer: not all the patients benefit from reinduction with carboplatin and paclitaxel. Med Sci Monit 2010; 16: CR549-54.

6. Ghazizadeh M, Sasaki Y, Araki T, Konishi H, Aihara K. Prognostic value of proliferative activity of ovarian carcinoma as revealed by PCNA and AgNOR analyses. Am J Clin Pathol 1997; 107: 451-8.

7. Kakeji Y, Korenaga D, Tsujitani S, Haraguchi M, Maehara Y, Sugimachi K. Predictive value of Ki-67 and argyrophilic nucleolar organizer region staining for lymph node metastasis in gastric cancer. Cancer Res 1991; 51: 3503-6.

8. Nakae S, Nakamura T, Ikegawa R, Yoshioka H, Shirono J, Tabuschi Y. Evaluation of argyrophilic nucleolar organizer region and proliferating cell nuclear antigen in colorectal cancer. J Surg Oncol 1998; 69: 28-35.

9. Mauri FA, Scampini S, Aldovini D, Ferrero S, Barbareschi M, Dalla Palma P. AgNOR distribution in serous tumours of the ovary. Pathologica 1990; 82: 487-92.

10. Gottwald L, Danilewicz M, Suzin J, Bienkiewicz A. Assessment of the AgNORs count in serous ovarian cancer. Ginekol Pol 2004; 75: 770-5.

11. Criscuolo M, Martinelli AM, Migaldi M, et al. Prognostic significance of nucleolar organizer regions in ovarian epithelial tumors. Int J Gynecol Pathol 1993; 12: 259-63.

12. Sujathan K, Kannan S, Raveendran-Pillai K, Chandralekha B, Sreedevi-Amma N, Krishnan-Nair M. Significance of AgNOR count in differentiating malignant cells from reactive mesothelial cells in serous effusions. Acta Cytologica 1996; 40: 724-8.

13. Miller B, Morris M, Silva E. Nucleolar organizer regions: a potential prognostic factor in adenocarcinoma of the endometrium. Gynecol Oncol 1994; 54: 137-41.

14. Wierzchniewska A, Wagrowska-Danilewicz M, Danilewicz $M$. Value of AgNOR counts and morphometric analysis of nuclear parameters in premalignant and malignant lesions of the uterine cervix. Pol J Pathol 1998; 49: 297-301.

15. Kumar A, Kushwaha AK, Kumar M, Gupta S. Argyrophilic nucleolar organizer regions: their value and correlation with clinical prognostic factors in breast carcinoma. J Surg Oncol 1997; 65: 201-4.

16. Ceccarelli C, Trere D, Santini D, Taffurelli M, Chieco P, Derenzini M. AgNORs in breast tumours. Micron 2000; 31: 143-9.

17. Chiusa L, Galliano D, Formiconi A, Di Primio O, Pich A. High and low risk prostate carcinoma determined by histologic grade and proliferative activity. Cancer 1997; 79: 1956-63.

18. Atallah AM, Tabll AA, El-Nashar E, et al. AgNORs count and DNA ploidy in liver biopsies from patients with schistosomal liver cirrhosis and hepatocellular carcinoma. Clin Biochem 2009; 42: 1616-20.

19. Nakamura M, Sano K, Kitagawa Y, Ogasawara T, Nishizawa S, Yonekura Y. Diagnostic significance of FDG-PET and argyrophylic nucleolar organizer regions (AgNORs) in oral squamous cell carcinoma. Oral Oncology 2004; 40: 190-8. 
20. Alaeddini M, Khalili M, Tirgary F, Etemad-Moghadam S. Argyrophylic proteins of nucleolar organizer regions (AgNORs) in salivary gland mucoepidermoid carcinoma and its relation to histological grade. Oral Surg Oral Pathol Oral Radiol Endod 2008; 105: 758-62.

21. Sirri V, Roussel P, Hernandez-Verdun D. The AgNOR proteins: qualitative and quantitative changes during the cell cycle. Micron 2000; 31: 121-6.

22. Howell WM, Black DA. Controlled silver-staining of nucleolus organizer regions with a protective colloidal developer: a 1-step method. Experimentia 1980; 36: 1014-5.

23. Mourad WA, Setrakian S, Hales ML, Abdulla M, Trucco G. The argyrophilic nucleolar organizer regions in ductal carcinoma in situ of the breast. Cancer 1994; 74: 1739-5

24. Ofner D, Schmid KW. Standardized AgNOR analysis: its usefulness in surgical oncology. Histochem Cell Biol 1996; 106: 193-6.

25. Crocker J, Boldy D, Egan M. How should we count AgNORs? Proposals for a standardized approach. J Pathol 1989; 158: 185-8.

26. Ploton D, Menager M, Jeannesson P, Himber G, Pigeon F, Adnet J. Improvement in the staining and in the visualization of the argyrophilic proteins of the Nucleolar Organizer Regions at the optical level. Histochem J 1986; 18: 5-14.

27. Kalloniemi OP, Punnonen R, Mattila J, Lehtinen M, Koivula T. Prognostic significance of DNA index, multiploidy and S-phase fraction in ovarian cancer. Cancer 1988; 61 : 334-9.

28. Gottwald L, Danilewicz M, Suzin J, et al. Assessment of the argyrophylic nucleolar organizer regions area/nucleus ratio in ovarian serous epithelial adenomas, borderline tumors and cancers. Arch Med Sci?2013; 9: 79-85.

29. Trabucco S, Varcaccio-Garofalo G, Botticella MA, De Stefano R, Capursi T, Resta L. Expression of AgNORs in serous ovarian tumors. Eur J Gynecol Oncol 1994; 15: 222-9.

30. Zergeroglu S, Aksakal O, Demirturk F, Gokmen O. Prognostic importance of the nucleolar organizer region score in ovarian epithelial tumors. Gynecol Obstet Invest 2001; 51: 60-3.

31. Sah SP, Dawar R, Kumar L, Gupta SD. Nucleolar organizer regions as a prognostic indicator in epithelial cancers of the ovary. Int I Gynecol Pathol 2004; 23: 347-53.

32. Gottwald L, Danilewicz M, Suzin J, Bienkiewicz A. The assesment of argyrophylic nucleolar organizer regions (AgNORs) count in serous ovarian neoplasms. Prz Menopauzalny 2003; 7: 38-41.

33. Gottwald L, Danilewicz M, Suzin J, Wójcik-Krowiranda K, Bienkiewicz A. AgNORs count correlates better than grading with the effect of chemotherapy in serous ovarian cancer. Pol J Pathol 2003; 54: 239-42.

34. Cucer N, Imamoglu M, Tozak H, et al. Two-dimentional agnor evaluation as a prognostic variable in bladder carcinoma: a different approach via total agnor/nucleus area per cell. Micron 2007; 38: 674-9.

35. Muso H. Long-term prognostic factors for chemotherapy of ovarian cancer. Osaka City Med J 1998; 44: 155-71.

36. Franck J, Longuespee R, Wisztorski M, et al. MALDI mass spectrometry imaging of proteins exceeding 30000 daltons. Med Sci Monit 2010; 16: BR293-9. 